travelled uncharted territory. But has she really answered her own question? Societies "intent on preserving the sharp social and intellectual distinctions between the sexes" have, for the most part, deliberately cultivated perceived sexual differences. But what are these? Do they indeed exist; if so, what difference does the difference make?

Here these questions are posed rather than answered. Unravelling the multifarious strands of women's role in the history of modern science is an essential first step, brilliantly executed in this book. It is to be hoped that this study will pro- voke further analysis into the contemporary scene and present powerful trends in science. For every Maxine Singer, now President of the Carnegie Institution of Washington, there are still hundreds of others striving to make their mark in the scientific enterprise in conditions where Catch-22 traps still operate. Will it be ever thus? Sometimes I'm optimistic, but reading what happened in history, and not yet discerning overpowering new trends, sometimes I wonder whether such optimism is justified.

June Goodfield is at The Manor House, Alfriston, Polegate, Sussex BN26 5SY, UK.

\section{Asking questions}

\section{Igor Aleksander}

Ideas and Information: Managing in a High-tech World. By Arno Penzias. W.W. Norton: 1989. Pp. 224. \$17.95, £12.95.

For many people, phrases such as 'the information age' or 'high-tech world' evoke feelings of the hackneyed, the oversold. Not so for Arno Penzias, who sees 'managing in a high-tech world' as a matter of exciting discovery and wonderment. In Ideas and Information, Penzias, a Nobel laureate for physics in 1979, glances over his own specialist fence at the nature of information technology and the effects it has had on him and the world he inhabits. The world 'managing' in the subtitle is used in the sense of 'coping': Penzias is a technology enthusiast. His book is intended to give heart to those who feel that coping in a world of faxes, electronic mail, word processing, databases and the like is getting beyond them.

The style is anecdotal without being trivial, authoritative without being overpowering. And it has to be enthusiastic because, after all, Penzias is the vicepresident for research of one of the world's most renowned information-technology companies: AT\&T's Bell Telephone Laboratories. The anecdotes add fun and a personal touch to what could so easily otherwise have been yet another dull catalogue of the benefits bestowed on mankind by the advent of computers. Penzias also goes to great lengths to distinguish the rule-enslaved computer from the free-learning, exploration-loving human being. I suppose that there are still those who get the two confused to the extent that such descriptions are necessary.

The book is written with an implied sense of history: the history of symbols, the history of mathematics and the history of computing machines. Penzias argues that the manipulation of symbols distinguishes computers from other machines in the way that being able to use symbols distinguishes human beings from animals.
Symbols were valued by the prehistoric painters of the images in the Lascaux caves in France, by the Sumerians of 3300 $\mathrm{BC}$ who invented information storage (tokens in a clay jar), and by the Egyptians and the Chinese, who raised application of their intelligence to higher planes by inventing numbers and mathematics. So, for Penzias, the computer is the ultimate celebration of human intelligence: a machine that embodies the finest points of the use of symbols and manipulations.

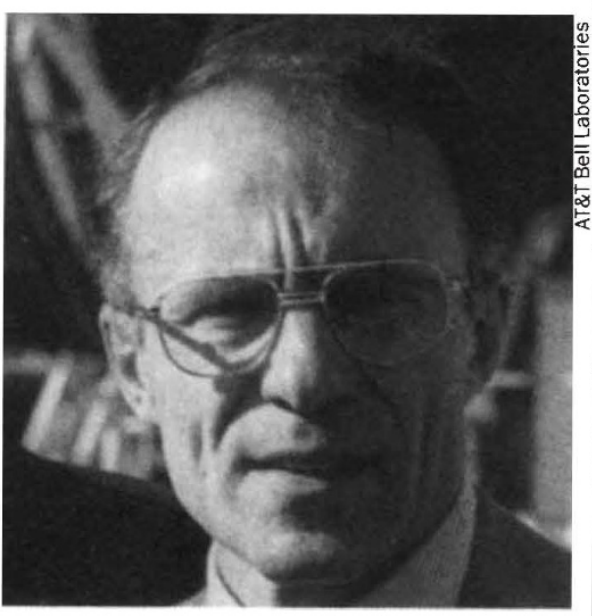

Arno Penzias - "cheerful optimism".

He does not confuse person and machine, however, as seen in this almost thrown-away footnote: "As we explore the computer's ability to match human information-processing capabilities, we shouldn't overlook the fact that these machines have much to offer society without emulating humans". At the same time as he creates the distinction between living and mechanical information processors, he pinpoints the very factor which, if mechanized, could reduce this crucial distance: "On the other hand, I am sure that this situation will change drastically when (and if) we can devise a computing architecture that learns from examples, the way humans do, rather than merely obeying instructions. Nature produces countless billions of such computers in the brains of living creatures". In these sentences he has identified (perhaps unwittingly) the scent that the contem- porary hounds of neural-network research have sniffed out, and that is leading them towards learning computers with which they will try to revolutionize computing by narrowing the gap between the mechanical and the biological.

The mix of anecdote, history and insightful comment is a characteristic of the book as a whole. Penzias describes milestones in the making of information machines such as Chomsky's analysis of language, Hopfield's revival of neural nets and Joseph Weizenbaum's totally mechanical 'psychiatrist emulator', Eliza, which makes its interlocutors think that it 'understands' their problems, while it is simply throwing their own words, modified by a few simple rules, back at them.

For me, a high point is reached in Penzias's recounting of I.I. Rabi's description of the reasons for his (Rabi's) success, also crowned by the Nobel prize in physics. "Have you asked any good questions today?", his mother would ask him on his return from school. This, surely, rather than just the ability to learn, must be the factor that best distinguishes organisms that possess intelligence from those that do not. The ones that do ask very good questions.

There are some unfortunate blemishes. Bell Labs is presented as the source of all discovery, which will irritate readers who happen to know that not all high-tech inventions were made at that institution. For example, the comment "At Bell Labs . . a robotics research group has built a robot that can follow spoken instructions" is followed by a description of work that was done by Terry Winograd at the Massachusetts Institute of Technology in the early 1970 s. There is no mention of Winograd. Even Hopfield is described as a Bell Labs' physicist, giving no credit to the fact that he is also an academic at Caltech.

But perhaps the worst sin is that there is no mention of the down side of computers: the overrating of technology for its own sake; the fact that the purchase of information technology in a badly managed organization can amplify the bad management; the need to change one's behaviour to meet the needs of computerdriven procedures (as in banks); new opportunities for fraud; the possibility that people may be forced to become less skilled as well as more skilled. For Penzias these difficulties do not exist, or if they do he may have decided to ignore them for fear of damaging the up-beat tempo of his book. Without a doubt those who need reassurance about coping in the information age will be rewarded by the cheerful optimism purveyed in Ideas and Information. Why spoil it with bad news?

Igor Aleksander is in the Department of Electrical Engineering, Imperial College, London SW7 5BT, UK 